\title{
Geomagnetic activity control on VHF scintillations over an Indian low latitude station, Waltair $\left(17.7^{\circ} \mathrm{N}, 83.3^{\circ} \mathrm{E}, 20^{\circ} \mathrm{N} \operatorname{dip}\right)$
}

\author{
D S V V D Prasad, P V S Rama Rao, G Uma, S Gopi Krishna and K Venkateswarlu \\ Department of Physics, Andhra University, Visakhapatnam 530 003, India.
}

\begin{abstract}
Using the data of amplitude scintillations recorded at $244 \mathrm{MHz}$ from the geostationary satellite, FLEETSAT $\left(73^{\circ} \mathrm{E}\right)$ at a low latitude station, Waltair $\left(17.7^{\circ} \mathrm{N}, 83.3^{\circ} \mathrm{E}, 20^{\circ} \mathrm{N}\right.$ dip $)$, during the increasing sunspot activity period of 1997-2000, the effect of the geomagnetic storms on the occurrence of ionospheric scintillations has been studied. A total of 60 SC storms studied during this period, following the Aarons' criterion, reveals that the local time of onset of the recovery phase of the geomagnetic storms play an important role in the generation or inhibition of the ionospheric irregularities. Out of the 60 storms studied, nearly 60 to $70 \%$ satisfied the categories I, II and III of Aarons' criteria. However, in the remaining 30 to $40 \%$ of the cases, no consistent results were observed. Thus, there is a necessity for further investigation of the effect of geomagnetic storms on ionospheric irregularities, particularly with reference to the altitude variations of the F-layer (h'F) relating to the changes in the local electric fields.
\end{abstract}

\section{Introduction}

The satellite radio beacon measurements because of their better time resolution, relative accuracy and potential for data continuity became a valuable and effective technique for the study of geomagnetic disturbances such as storms on ionospheric electron density and irregularities. During these events ionosphere shows a variety of effects, which may depend on season, geographic latitude, local time and the time of onset of the storm. Dynamic effects that can influence the ionosphere during these events are due to the upward or downward motion of the ionization caused, either by electric fields or neutral winds and the field aligned flow of ionization between ionosphere and magnetosphere.

Magnetic disturbances such as geomagnetic storms, their associated effects on the ionized and the neutral plasma of the ionospheric F-region remains as one of the interesting topics of study of the upper atmospheric physics. These disturbances have profound influence on the global morphology of the upper atmosphere and constitute one of the important links in understanding the complex solar terrestrial relations. The study of solar-terrestrial relation is also of practical importance because the trans-ionospheric radio communications and satellite ephemeris predictions are severely degraded during these disturbances. Magnetic storms introduce dynamical and electrodynamical changes in the ionosphere resulting from the solar-wind-magnetospheric interactions. Although many experimental observations and their statistical results are available relating to the average behaviour of storm phenomena, there still remains some scientific interest in the short term (transients) and long term (recurrent) ionospheric effects during individual storm events (Abdu et al 1995), since the effects are known to differ from one storm to the other.

Aarons et al (1980) and Rastogi et al (1981) examined the effects of geomagnetic disturbances on equatorial and low latitude ionospheric

Keywords. Geomagnetic storms; VHF scintillations; maximum Dst excursion. 
scintillations and observed that with increase in the magnetic activity, the probability of occurrence of scintillation in trans-ionospheric signals increases during the post-midnight periods in all the longitude sectors, while the pre-midnight phenomenon depends on the season as well as on longitude. Aarons and Das Gupta (1984) and Das Gupta et al (1985) from their observation of intense equatorial scintillation activity in the post-midnight and morning hours following a severe geomagnetic storm, suggested that the probability of occurrence of post-midnight equatorial scintillation is enhanced if the recovery phase of the storm starts in the local midnight to dawn sector.

Yeh et al (2001) studied the storm time plasma irregularities in the pre-dawn hours at the low latitude during the 22nd October, 1999 geomagnetic storm and reported that pre-sunrise bubbles are positively correlated to the enhanced electric fields in response to the storm time disturbances which can significantly affect the occurrence time and spatial extent of the plasma irregularities in the low latitude ionosphere. Bhattacharya et al (2002) studied the effect of magnetic activity on the dynamics of equatorial F-region irregularities and found that larger values in the early phase of evolution of ESF irregularities during the post-sunset period with a steep decline in the height of the F-region are observed. It is also reported that in the post-midnight period an increase in the height of the F-region is observed due to the ionospheric zonal electric field turning from westward to eastward due to the effect of magnetic activity, which also generates fresh irregularities that produce the observed scintillations.

In this paper, an attempt is made to study the effects of geomagnetic storms on the occurrence or inhibition of ionospheric scintillations at VHF signal using Aarons' criteria (Aarons 1991) for different onset times and various phases of the storms and their association with the changes in the F-layer altitude.

\section{Data and analysis}

VHF scintillations data recorded at a low latitude station, Waltair $\left(20^{\circ} \mathrm{N}\right.$ Dip $)$ for the period from 1997 to 2000, is used in the present study. Magnetic data of Hyderabad $\left(17.3^{\circ} \mathrm{N}, 78.5^{\circ} \mathrm{E}\right)$, the closest station to Waltair $\left(17.7^{\circ} \mathrm{N}, 83.3^{\circ} \mathrm{E}\right)$, is used along with the above data. The values of the geomagnetic indices, $K_{p}$ and Dst (available from SGD bulletins) are used to study the effect of geomagnetic activity on the generation and inhibition of irregularities producing VHF scintillations. VHF scintillation data and the ionosonde data simultaneously recorded at Waltair during the increasing sunspot activity period of 1997-2000 scaled for every 15 minutes interval is used for studying the effects of $h$ 'F variations on scintillation activity during the disturbed conditions.

A total of 60 Sudden Commencement (SC) type of magnetic storms which occurred during the above period are identified and chosen for the present study. The maximum excursion of Dst of these storms varied between 50 and $350 \mathrm{nT}$.

\section{Results}

In the equatorial ionosphere during the years of high solar flux, in the F-layer altitudes irregularities are produced in most of the nights during all seasons. However, there are some nights with no irregularities even during the high sunspot activity period. The hypothesis advanced by Aarons (1991) was that, one must look not only for the external seeding mechanisms alone, but also for the inhibiting factors. The ring current during magnetic storms plays a major role, directly or indirectly, in establishing the conditions necessary for equatorial F-layer irregularity generation or inhibition.

To illustrate the ionospheric response to geomagnetic storms, three typical storms observed during the above period, which were not contaminated by any other geomagnetic event and offer a clean background were chosen. Out of the $60 \mathrm{SC}$ storms that were studied for classification, one example from each of the three categories of the storms and its association with the occurrence or inhibition of scintillation activity over Waltair are presented in figures 1, 2 and 3 along with the corresponding $K_{p}$ index and the ionospheric F-layer altitude changes over Waltair. The behaviour of these individual geomagnetic storms and their association with the VHF scintillation activity and the virtual height of the F-layer with special reference to Aarons' criteria are discussed in the following sections.

\subsection{Storm of 23rd April 1998 (category I)}

Figure 1 shows the magnetic storm of 23rd April, 1998 along with the corresponding Dst and $K_{p}$ indices in the two middle panels. In the top panel, the ionospheric F-layer altitude and in the bottom panel, the scintillation and spread-F occurrences over Waltair are presented. The sudden commencement of this magnetic storm occurred at $2355 \mathrm{hrs}$ IST on 23rd April 1998. After about an hour, the Dst started decreasing attaining the lowest value of $-87 \mathrm{nT}$ at $1300 \mathrm{hrs}$ IST on the following day i.e., 24th April, when the $A_{p}$ index was 35 and the $K_{p}$ index varied from 1 to $6^{\circ}$. From the top panel, it may be seen that during this period, no 
CATEGORY I
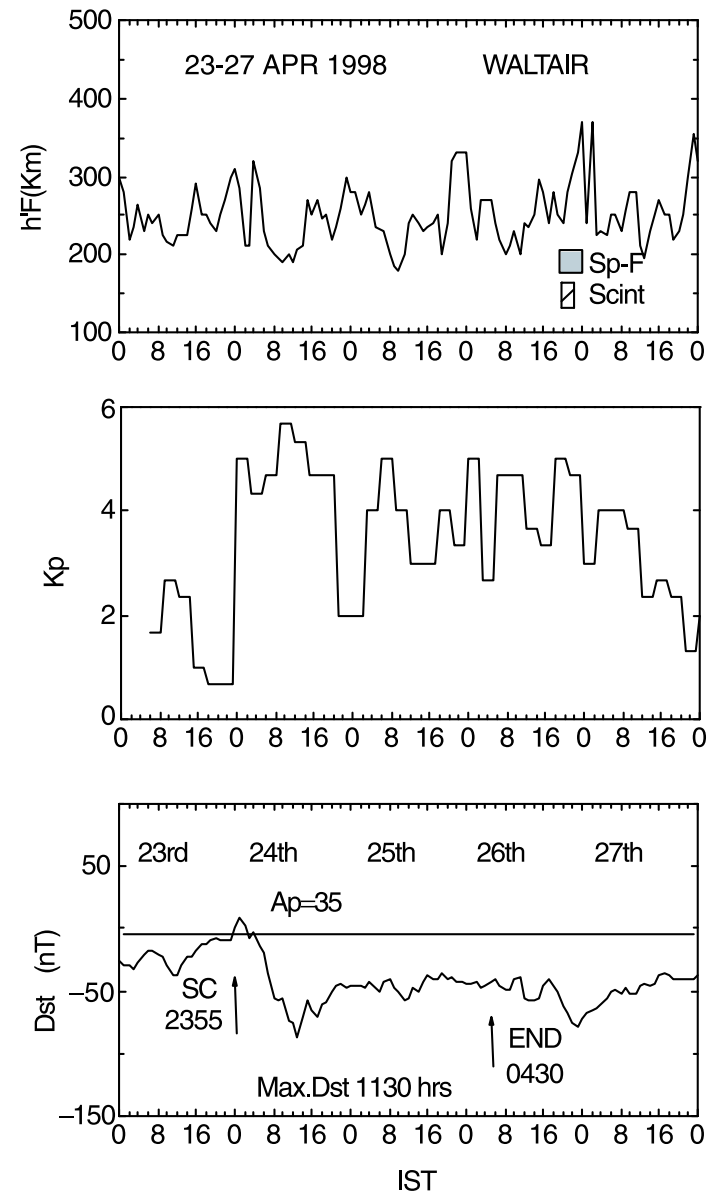

Figure 1. Typical example of a magnetic storm that occurred during 23rd-27th April 1998 which satisfies Aarons' criterion I.

significant height rise of F-layer is observed and the irregularities are inhibited during the night. This feature follows the category I of Aarons' criteria. It may also be seen that after the end of the storm (0430 hrs IST) i.e., on 26th April, scintillations occurred during 2000-2330 hrs IST during which period the F-layer altitude increased from 300 to $390 \mathrm{~km}$ and then decreased to about $225 \mathrm{~km}$ enabling the conditions conducive for the generation of irregularities, which however are not related to this particular magnetic storm.

\subsection{Storm of 15th July 2000 (category II)}

In figure 2 , is presented the variation of a severe magnetic storm which occurred on 15th July, 2000. The sudden commencement of this storm occurred at 2008 hrs IST reaching a maximum Dst value of $-300 \mathrm{nT}$ after midnight i.e., at $0330 \mathrm{hrs}$ IST (i.e., in the early hours of 16th July), when $A_{p}$ index was 164 and the $\mathrm{K}_{\mathrm{p}}$ index varied from $3^{-}$to 9 . The height variations of the F-layer over Waltair on 16th July, where the maximum excursion of Dst
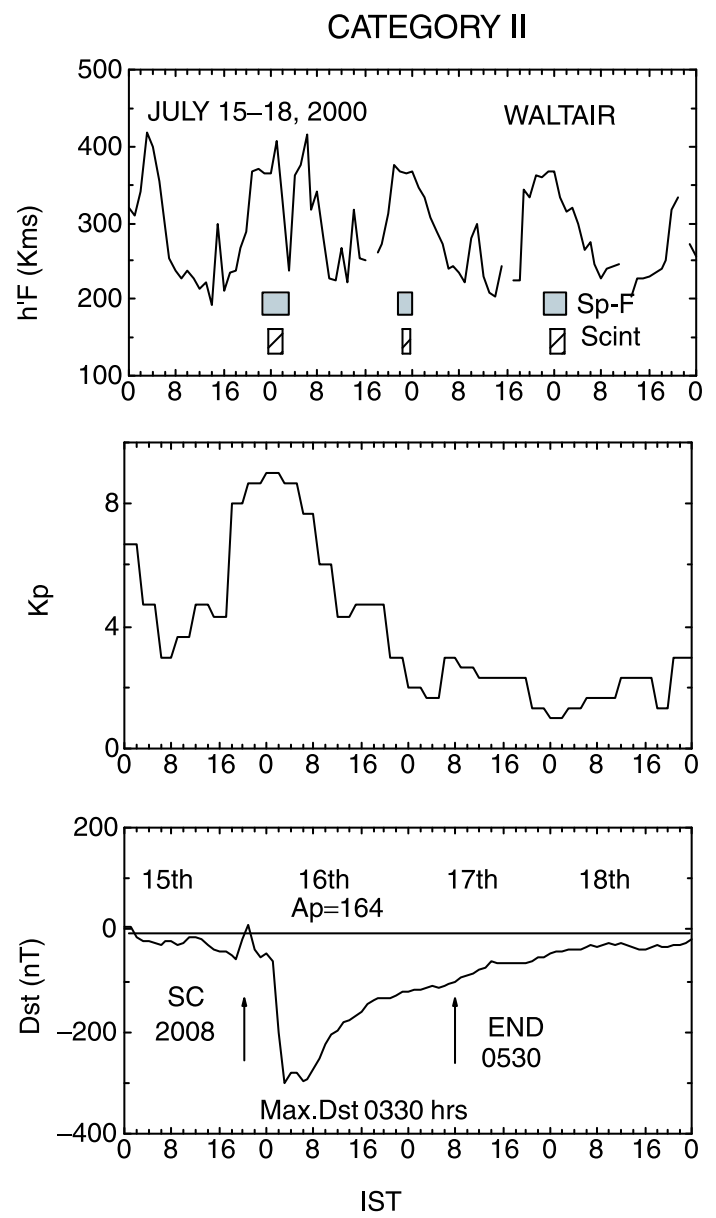

Figure 2. Typical example of a magnetic storm that occurred during 15th-18th July 2000 which satisfies Aarons' criterion II.

occurred, showed a large increase (up to $400 \mathrm{~km}$ ) in the F-layer altitude contributing to the favourable conditions for the generation of irregularities during the recovery phase of this storm and scintillations occurred from $2200 \mathrm{hrs}$ to $0000 \mathrm{hrs}$ IST of 16th July, which justify Aarons' criteria II. The delayed disturbance dynamo-electric fields (Basu et al 2001) must have contributed to the increase in the F-layer altitude over these latitudes thus enabling the generation of irregularities.

\subsection{Storm of 17th April 1998 (category III)}

The storm which occurred during 17th-19th April 1998 and shown in figure 3 is an example of a weak storm. The sudden commencement of the storm at $0753 \mathrm{hrs}$ IST on 17th April attained a maximum Dst of $-46 \mathrm{nT}$ at $2130 \mathrm{hrs}$ IST on the same day and the $A_{p}$ value was 14 and the $K_{p}$ varied from $2^{-}$to $4^{+}$. At the time of maximum Dst excursion of this storm, which occurred between the sunset and premidnight hours, the F-layer altitude did not change and the irregularities that occurred were similar 

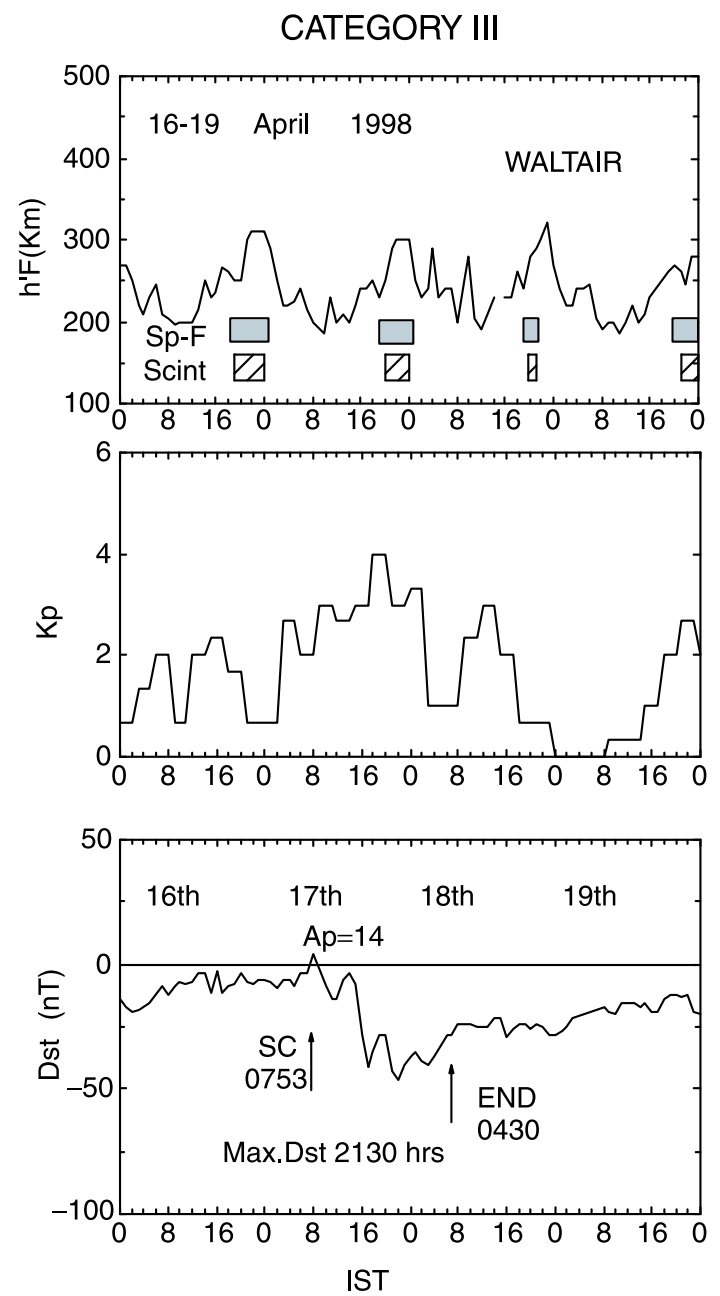

Figure 3. Typical example of a magnetic storm that occurred during 16th-19th April 1998 which satisfies Aarons' criterion III.

to an undisturbed night (category III). Further, it may also be noticed from this figure that strong scintillations are observed on all the nights during this period, irrespective of the phase of the storm.

From a statistical classification of all the $60 \mathrm{SC}$ storms studied, the maximum percentage of storms that satisfy category I of Aarons' criteria in the occurrence of scintillations with a large excursion of Dst occurring before sunset hours is higher $(71 \%)$ followed by categories II (69\%) and III (62\%). In the remaining 30 to $40 \%$ of cases not satisfying this criteria, these have to be further examined in relation to the effect of the local storm time electric fields.

\section{Discussion}

The pattern of generation and inhibition of scintillations during geomagnetic disturbance as explained by Aarons (1991) indicates that the magnetospheric electric fields are shielded by the changes developed in the ring current from being penetrated into the ionospheric levels under specific conditions, and thus inhibit the necessary condition for the generation of irregularities. Ionospheric measurements often indicate that during magnetically disturbed conditions the low latitude electric fields and currents undergo large departures from their quiet time averages (Somayajulu et al 1994; Sobral et al 1997). The highly variable disturbance drifts result from a complex interplay of electrodynamic processes driven by magnetospheric electric fields and currents and by enhanced energy input into the high latitude thermosphere (Fejer and Scherliess 1995). Most of the low latitude disturbance plasma drifts associated with magnetic activity are explained by the combined effects of prompt penetration electric fields (Spiro et al 1988) and thermodynamic wind driven disturbance dynamo electric fields (Blanc and Richmond 1980).

Banola et al (2001) studied the effect of geomagnetic activity on VHF scintillations recorded at an equatorial station, Trivandrum and a low latitude station, Mumbai during the high sunspot activity period of 1989-91 in the case of about 77 storms using Aarons' criteria. It was reported that a maximum percentage $(70 \%)$ of storms satisfy Aarons' criteria when a large excursion of Dst occurs during midnight to post-midnight (category II), compared to the other two categories (I and III) in the Indian region during the high solar activity period, but nearly $40 \%$ of cases do not satisfy the generation and inhibition of scintillation activity in the other two categories (I and III).

As the nature and behaviour of each individual geomagnetic storm and its associated effects on ionospheric F-region irregularities has profound influence on global trans-ionospheric communications, these studies need to be continued with larger data base and with any other probable mechanisms responsible for the generation or inhibition of irregularities. These mechanisms are also to be examined with respect to the changes in the local electric fields strongly believed to be responsible for the equatorial and low latitude ionospheric scintillations.

\section{Acknowledgement}

One of the authors (PVS) is grateful to CSIR, Govt. of India for providing him with an Emeritus Scientist project.

\section{References}

Aarons J, Mullen J P, Koster J R, deSilva $\mathrm{R} F$, Madeiros R T, Bushby A, Pantoja J, Lanat J and Paulson M R 1980 Seasonal and geomagnetic control of 
equatorial scintillations in two longitudinal sectors; J. Atmos. Terr. Phys. 42 861-866.

Aarons J and Das Gupta A 1984 Equatorial scintillations during the major magnetic storm of April 1981; Radio Sci. 19 731-739.

Aarons J 1991 The role of the ring current in the generation and inhibition of equatorial F-layer irregularities during magnetic storms; Radio Sci. 26 1131-1149.

Abdu M A, Batista I A, Walker G O, Sobral J H A, Trivedi N B and Depaula E R 1995 Equatorial electric fields during magnetospheric disturbances: Local time/longitude dependencies from recent EITS campaigns; J. Atmos. Terr. Phys. 57 1065-1083.

Banola S, Pathan B M and Rao D R K 2001 Strength of the equatorial electrojet and geomagnetic activity control on VHF scintillations at the Indian longitudinal zone; Ind. J. Radio \&s Space Phys. 30 163-171.

Basu Su, Basu S, Valladares C E, Yeh H C, Su S Y, Mackenzie E, Sultan P J, Aarons J, Rich F J, Doherty P, Groves K M and Bullett T W 2001 Ionospheric effects of major magnetic storms during the international space weather period of September and October 1999: GPS observations, VHF/UHF scintillations, and in situ density structures at middle and equatorial latitudes, $J$. Geophys. Res. 106 30389-30413.

Bhattacharya A, Basu S, Groves K M, Valladares C E and Sheehan R 2002 Effect of magnetic activity on the dynamics of equatorial F-region irregularities; J. Geophys. Res. 107 1489-1495.
Blanc M and Richmond A D 1980 The ionospheric disturbance dynamo, J. Geophys. Res. 851669.

Das Gupta A, Maitra A and Das S K 1985 Post midnight equatorial scintillation activity in relation to geomagnetic disturbances; J. Atmos. Terr. Phys. 47 911-916.

Fejer B G and Scherliess L 1995 Time dependent response of equatorial ionospheric electric fields to magnetospheric disturbances, Geophys. Res. Lett. 22851.

Rastogi R G, Mullen J P and MacKenzie E 1981 Effect of geomagnetic activity on equatorial VHF scintillations and spread-F; J. Geophys. Res. 86 3661-3664.

Sobral J H A, Abdu M A, Gonzalez W D, Tsurutani B T, Batista I S, Gonzalez A L C 1997 Effects of intense storms and substorms on the equatorial ionosphere/thermosphere system in the American sector from ground based and satellite data, J. Geophys. Res. 10214305.

Somayajulu V V, Krishnamurthy B V and Subbarao K S V 1994 Response of night time equatorial F-region to magnetic disturbances, J. Atmos. Solar. Terr. Phys. 53 956.

Spiro R W, Wolf R A and Fejer B G 1988 Penetration of high latitude electric field effects to low latitudes during SUNDIAL 1984, Annales Geophysicae 639.

Yeh H C, Su S Y and Heelis R A 2001 Storm time plasma irregularities in the pre-dawn hours observed by the low latitude ROCSAT - 1 satellite at $600 \mathrm{~km}$ altitude; Geophys. Res. Lett. 28 685-688. 